\title{
Anisotropy in Mechanical Properties and Fracture Behavior of an Oxide Dispersion Fe20Cr5Al Alloy
}

\author{
J. CHAO and C. CAPDEVILA
}

Anisotropy of fracture toughness and fracture behavior of Fe20Cr5Al oxide dispersionstrengthened alloy has been investigated by means of compression tests, hardness tests, and wedge splitting test. The results show a small effect of the compression direction on yield strength (YS) and strain hardening. The YS is minimum for longitudinal direction and maximum for the tangential direction. The transverse plastic strain ratio is similar for tangential and longitudinal directions but very different from that in normal direction. Hardness depends on the indentation plane; it is lower for any plane parallel to the L-T plane and of similar magnitude for the other orthogonal planes, i.e., the L-S and T-S planes. Macroscopically, two failure modes have been observed after wedge-splitting tests, those of LS and TS specimens in which fracture deviates along one or two branches normal to the notch plane, and those of LT, TL, SL, and ST specimens in which fracture propagates along the notch plane. Besides LT and TL specimens present delaminations parallel to L-T plane. Both, the fracture surface of branching cracks and that of the delaminations, show an intergranular brittle fracture appearance. It is proposed that the main cause of the delamination and crack branching is the alignment in the mesoscopic scale of the ultrafine grains structure which is enhanced by the $\langle 110\rangle$-texture of the material and by the presence in the grain boundaries of both yttria dispersoids and impurity contaminations. An elastoplastic finite element analysis was performed to study what stress state is the cause of the branches and delaminations. It is concluded that the normal to the crack branches and/or the shear stress components could determine the crack bifurcation mechanism, whereas the delamination it seems that it is controlled by the magnitude of the stress component normal to the delamination plane.

DOI: $10.1007 / \mathrm{s} 11661-014-2329-7$

(C) The Minerals, Metals \& Materials Society and ASM International 2014

\section{INTRODUCTION}

OXIDE dispersion-strengthened (ODS) ferritic stainless steels are considered the most promising structural materials for several types of reactors, including future fusion reactors, since it combines an acceptable creep rupture strength, excellent swelling resistance, and high corrosion resistance in supercritical pressurized water. ${ }^{[1]}$ These materials are usually produced by mechanical alloying (MA) of yttria nano-particles and pre-alloyed or elementary powders of $\mathrm{Fe}, \mathrm{Cr}, \mathrm{Al}$, and Ti elements. ${ }^{[2]}$ The resulting powders are vulnerable to impurity contamination due to the MA processing. The consolidation of the powders is performed by hot isostatic pressing and/or hot extrusion at about $1273 \mathrm{~K}$ to $1373 \mathrm{~K}\left(1000{ }^{\circ} \mathrm{C}\right.$ to $\left.1100{ }^{\circ} \mathrm{C}\right) \cdot{ }^{[2]}$ These thermomechanical processes led to the development of a bundle-like structure of elongated grains with isolated submicrometric particles stringers aligned with the extrusion/ rolling direction. Moreover, a strong $\langle 110\rangle$ fiber texture along extrusion/rolling direction is formed. Lower

J. CHAO, Head of Mechanical Testing Laboratory, and C. CAPDEVILA, Physicist, Researcher, are with the Centro Nacional de Investigaciones Metalurgicas (CENIM-CSIC), Avenida Gregorio del Amo 8, 28040 Madrid, Spain. Contact e-mail: jchao@cenim.csic.es Manuscript submitted April 15, 2013.

Article published online April 15, 2014 fracture toughness than conventional ferritic steel is one of the important factors limiting the use of ODS steels in the nuclear power industry. It is generally thought that MA of ferritic steels with $\mathrm{Y}_{2} \mathrm{O}_{3}$ particles is the cause of the degradation of the impact behavior of the steel. ${ }^{[3]}$ Another issue linked to the ODS steels is their pronounced anisotropic behavior in tensile elongation and ductile-brittle transition behavior coming from the fabrication route. ${ }^{[4]}$ It was suggested that the anisotropy of mechanical properties could be explained not by the texture but by the combined effect of the above described structure and segregation/precipitation/ inclusion of titanium. ${ }^{[5]}$ However, it was recently reported that the anisotropy of toughness is determined by three factors: distribution in size and shape of inclusions, microstructural anisotropy due to banding, and crystallographic texture. ${ }^{[6]}$ The anisotropy of toughness is a complex mechanical phenomenon that would depend not only on the chemical composition and the matrix microstructure (grain size, dislocations density, crystallographic texture...), but also on the mesoscopic grain morphology and the segregation and inclusion states of the alloy.

The objective of the present work is to characterize the mechanical and fracture behavior as a function of specimen orientation in a hot extruded tube. The mechanical behavior (yield strength, strain hardening and transverse plastic strain ratio) was analyzed by 
means of compression tests of cube specimens, whereas the fracture behavior was studied by means of wedge splitting test (WST) of notched cube specimens. From the finite element analysis of the experimental results of WST specimens, an attempt was made to evaluate the delaminations and crack bifurcation observed on the fracture surfaces.

\section{MATERIAL AND EXPERIMENTAL PROCEDURE}

\section{A. Material}

The PM 2000 alloy used in this study was provided by PLANSEE GmbH in the form of the as-rolled tube of $100-\mathrm{mm}$ diameter and 7-mm thickness. Material processing involved mechanical alloying, hot compaction, hot extrusion, and hot rolling $\left[\sim 1323 \mathrm{~K}\left(1050{ }^{\circ} \mathrm{C}\right)\right]$ into a tube. The material is subsequently air cooled to room temperature. During processing, no evidence of discontinuous dynamic recrystallization involving nucleation and growth of new grains was observed, in spite of that the hot extrusion and hot rolling stages were carried out at very high temperatures. The material during forming follows an extended recovery mechanism which is characterized by a gradual increase in misorientations between neighboring subgrains that were created by recovery processes at the earlier stages of deformation. ${ }^{[7]}$ The resulting dislocation substructure was a complex network of a mix of higher and lower angle walls characterized by misorientation angles not exceeding $20 \mathrm{deg} .{ }^{[8]}$ The microstructure consists of submicrometric grains elongated in the extrusion/rolling direction. ${ }^{\text {[9] }}$

The material presents a strong texture in which the $\langle 110\rangle$ crystalline directions remain parallel to longitudinal (L) and tangential (T) directions, whereas the $\langle 100\rangle$ direction is parallel to the short $(\mathrm{S})$ direction of the tube. ${ }^{[10]}$

Previous microstructure characterization showed anisotropic grain structure with equiaxed dimensions in the $\mathrm{T}-\mathrm{S}$ plane $(\approx 0.7 \mu \mathrm{m})$ but with significant elongation in $\mathrm{L}$ direction in the L-T and L-S planes $(\approx 1.6 \mu \mathrm{m}){ }^{[10]}$ Yttria particles with sizes ranging from 3 to $40 \mathrm{~nm}$ are mainly located at the grain boundaries. ${ }^{[10]}$ Besides, numerous large inclusions of $\gamma-\mathrm{Al}_{2} \mathrm{O}_{3}$ as well as $\gamma-\mathrm{Al}_{2} \mathrm{O}_{3} / \mathrm{Y}-\mathrm{Al}-\mathrm{O}$ inclusions with complex composition were found, which are preferentially forming considerably large stringers in L-S and L-T planes; however, stringers of this inclusions type were not found in T-S plane. ${ }^{[10]}$
The chemical composition of the alloy using X-ray fluorescence spectrometry and wet chemistry techniques is given in Table I.

\section{B. Mechanical Properties}

Compression tests were carried out on cube specimens of $6.2-\mathrm{mm}$ side, which were machined from thickness center of the pipe. The tests were performed on a $100 \mathrm{kN}$ capacity electromechanical testing machine (Microtest, model EM2/FR, Madrid, Spain) at room temperature at a crosshead speed of $0.2 \mathrm{~mm} / \mathrm{min}$, placing polytetrafluoroethylene (PTFE) sheets of $75-\mu \mathrm{m}$ thickness between the specimen and the plates to reduce friction and the related barrelling effect. The specimen shortening was obtained from their initial height and the crosshead displacement corrected by subtracting the previously obtained displacement components due to the compliance of the testing machine and compression test fixture. A final reduction in height of 10 pct was given to each specimen. The yield strength (YS), strain hardening $(n)$, and plastic strain ratio $(R)$ for $\mathrm{L}, \mathrm{T}$, and $\mathrm{S}$ compression directions (Figure 1) were determined. The strain hardening, n, was calculated at the 0.01 to 0.02 strain range as

$$
n=\frac{\mathrm{d} \sigma}{\mathrm{d} \varepsilon} \frac{\varepsilon}{\sigma}
$$

where $\sigma$ and $\varepsilon$ are the true stress and the true plastic strain, respectively. The transverse plastic strain ratio, $R$, for each orientation was calculated from the change in the dimensions of the cross section of the specimen after the test and was defined as

$$
R_{\mathrm{L}}=\frac{e_{\mathrm{T}}}{e_{\mathrm{S}}} ; R_{\mathrm{T}}=\frac{e_{\mathrm{L}}}{e_{\mathrm{S}}} ; R_{\mathrm{S}}=\frac{e_{\mathrm{T}}}{e_{\mathrm{L}}},
$$

where $e_{\mathrm{L}}, e_{\mathrm{T}}$, and $e_{\mathrm{S}}$ are the engineering plastic strain in $\mathrm{L}, \mathrm{T}$, and $\mathrm{S}$ directions, respectively. Five compression tests for each orientation were carried out.

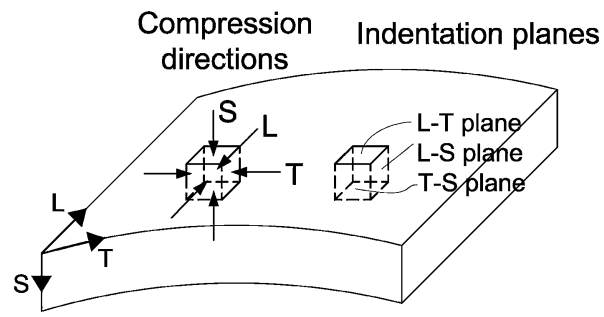

Fig. 1-Identification of the compression directions and indentation planes.

Table I. Chemical Composition of PM2000 Alloy

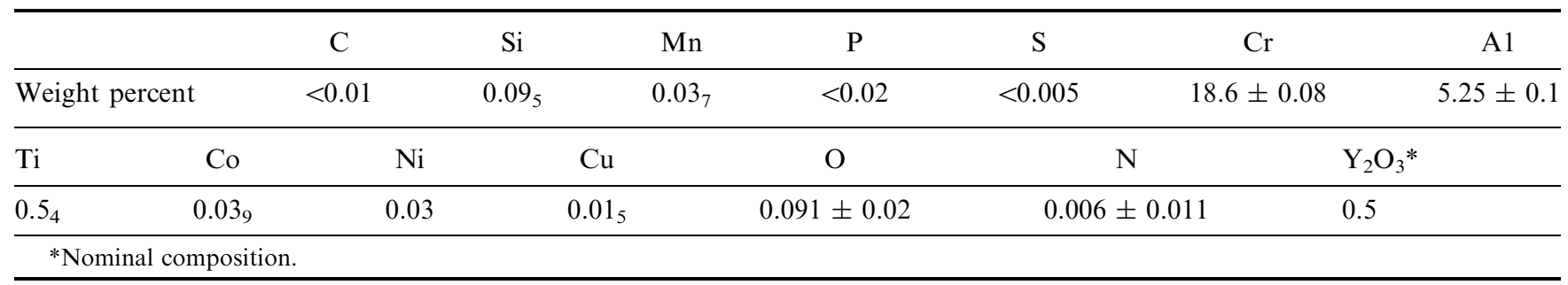



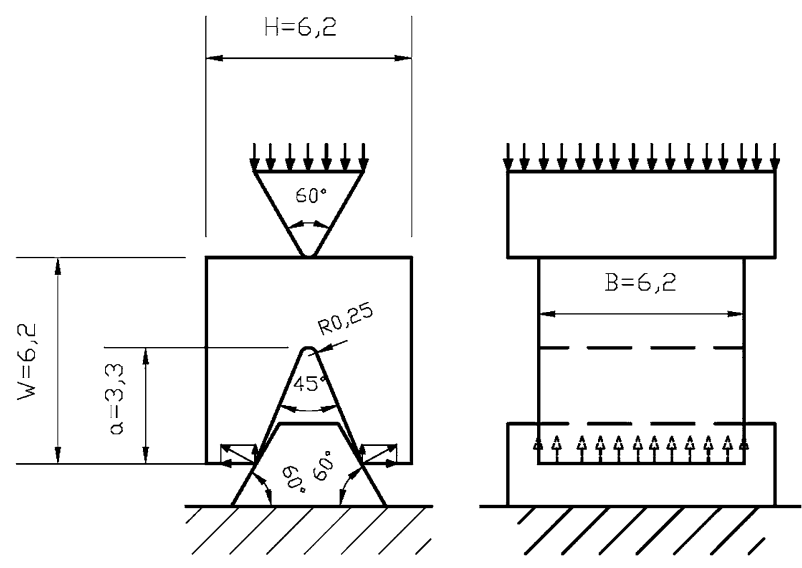

Fig. 2-Specimen geometry and loading procedure in wedge splitting test.

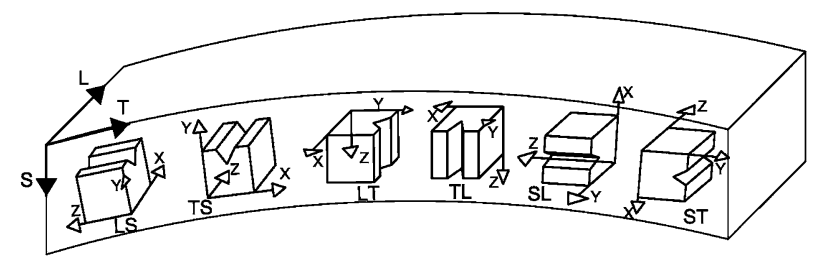

Fig. 3-Orientation and designation of specimens of wedge splitting test.

In order to corroborate the results of the compression tests, in particular those regarding to the transverse strain ratio, Vickers hardness measurements were performed on L-T, L-S, and T-S cross sections of the pipe (Figure 1) using $196 \mathrm{~N}$ load for 15 seconds.

The WST, often used for characterization of reinforced concrete and brittle materials ${ }^{[11]}$ and foods ${ }^{[12]}$, was adapted to evaluate the effect of the notch orientation on the fracture behavior of PM2000 alloy. The details of the specimen geometry and loading procedure are sketched in Figure 2. The directional configuration of the specimens for WST was designated using a two letter code: the first letter designates the normal direction to the notch plane, and the second letter the expected direction of fracture propagation, as defined in ASTM standard. ${ }^{[13]}$ The notch orientations of wedge splitting specimens regarding the tube geometry presented in Figure 3 were considered in this study. Four WSTs were carried out for each notch orientation. The specimens were compressed to failure at a crosshead speed of $0.5 \mathrm{~mm} / \mathrm{min}$ at room temperature using Molikote ${ }^{\circledR}$ G-Rapid-Plus (Dow Corning Europe, Belgium) as a lubricant to reduce the friction between the loading plunger and the support, and the specimen. The fracture of the broken specimens was macroscopically analyzed in low magnifications with a stereoscopic binocular microscope.

The stress distribution in front of the notch root of notched specimens at the fracture load was evaluated using finite element method. In all the notch positions, the coordinate $x$-axis is normal to the notch plane, whereas $\mathrm{y}$ and $\mathrm{z}$ axes are parallel to the axis and to the basis of the notch, respectively, Figures 3 and 4 .

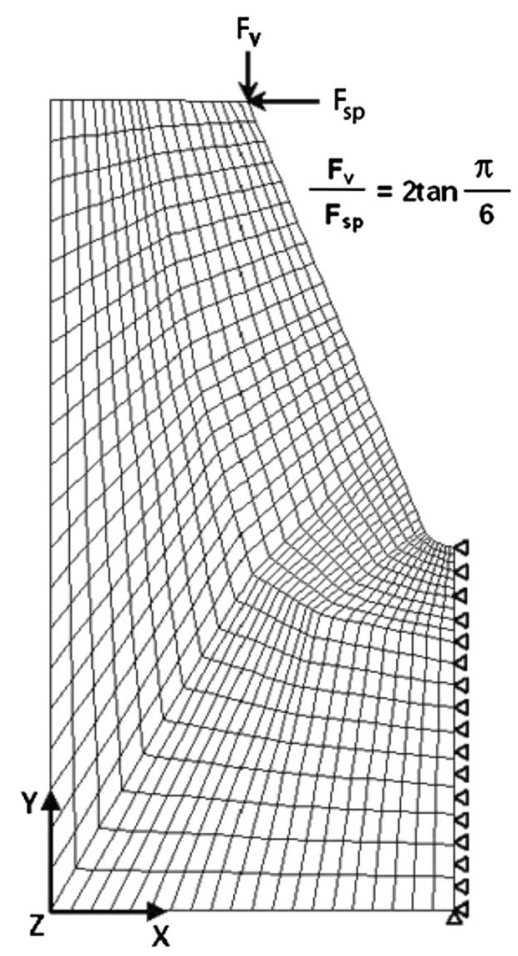

Fig. 4-Finite element model of WST used for calculation of the stress distribution.

Calculations were made using 8-node isoparametric elements assuming plane strain conditions of the specimen. Because the below reported differences in YS and $\mathrm{n}$ with orientation are small, the material was modelled as an elastoplastic material with an isotropic Von Mises plasticity criterion and isotropic work hardening in which Young's modulus was $200 \mathrm{GPa}$, and the Poisson's ratio was 0.3. Small scale yielding was assumed. According to previous work, ${ }^{[14]}$ the flow stress curve was defined by the expression:

$$
\sigma=1020+86 \cdot \varepsilon_{\mathrm{p}}^{0.505}
$$

Figure 4 shows the mesh used for the calculations. Due to symmetry, it was only necessary to model half of the specimen. The nodal load was incrementally applied step by step on the corner nodes of the notch mouth, maintaining a vertical $\left(F_{\mathrm{v}}\right)$ to splitting $\left(F_{\mathrm{sp}}\right)$ force ratio of

$$
\frac{F_{\mathrm{v}}}{F_{\mathrm{sp}}}=2 \cdot \tan \frac{\pi}{6}
$$

Convergence of results was reached using a mesh consisting of 1600 elements and 5042 nodes. Combining experimental results with finite element calculations enabled the determination of the critical stress state from the load steps in which specimens had fractured during WST. Because the critical stress state was considered to be determined by both, the magnitude of splitting load and the failure mode, different designations were used. However, it is clear that disregarding of the notch position, the finite element model is the same because of the isotropy hypothesis above stated. 


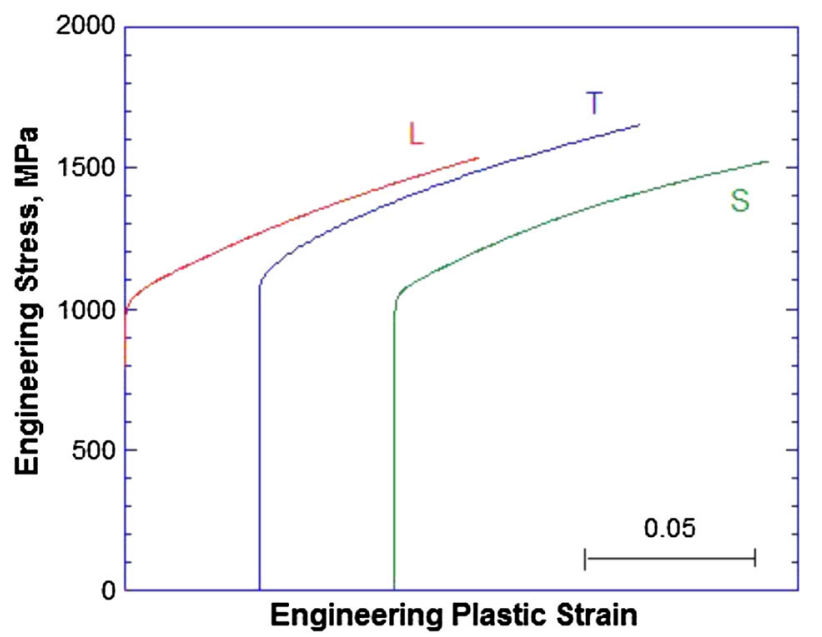

Fig. 5-Engineering stress-engineering plastic strain curves of compression tests in $\mathrm{L}, \mathrm{T}$, and $\mathrm{S}$ test directions.

\section{RESULTS AND DISCUSSION}

\section{A. Compression Tests}

Typical engineering stress-strain plastic strain curves for longitudinal (L), transverse (T), and short transverse (S) are shown in Figure 5. All the curves showed continuous yield behavior.

Transverse plastic strain ratio is similar for tangential and longitudinal test directions of the tube but very different from that in normal direction, Figure 6(a), which reveals that plastic strain in $\mathbf{S}$ direction is considerably higher than that in the $\mathrm{T}$ direction, when the compression direction is parallel to L direction, and that in the L direction, when the compression is applied in $\mathrm{T}$ direction. It can be said that for compression in the plastic regimen in $\mathrm{L}$ and $\mathrm{T}$ directions, near plane strain conditions prevail on the L-S and T-S planes of the material, respectively. In the case of compression along $\mathrm{S}$ direction, the plastic deformation in $\mathrm{T}$ direction and $\mathrm{L}$ direction is very similar.

Figure 6(b) shows the plot of 0.2 pct yield strength YS vs the direction of the compression axis (solid circles). For comparative purposes, the value of the tensile YS in L direction previously obtained ${ }^{[10]}$ is also plotted in Figure 6(b). In addition, in this figure, the calculated values of YS according to the Hill's theory of plastically anisotropic materials ${ }^{[15]}$ were also plotted. These values were calculated using the following expressions:

$$
\begin{aligned}
\sigma_{\mathrm{YS}(\mathrm{L})} & =\left[H\left(1+1 / R_{\mathrm{L}}\right)\right]^{-1 / 2} ; \sigma_{\mathrm{YS}(\mathrm{T})}=\left[H\left(1+1 / R_{\mathrm{T}}\right)\right]^{-1 / 2} ; \\
\sigma_{\mathrm{YS}(\mathrm{S})} & =\left[H\left(1 / R_{\mathrm{L}}+1 / R_{\mathrm{T}}\right)\right]^{-1 / 2},
\end{aligned}
$$

where $R_{\mathrm{L}}, R_{\mathrm{T}}$, and $R_{\mathrm{S}}$ have been experimentally determined, and $\mathrm{H}$ is a constant that is determined applying the least square method to the differences between experimental and calculated yield stresses. ${ }^{[16]}$

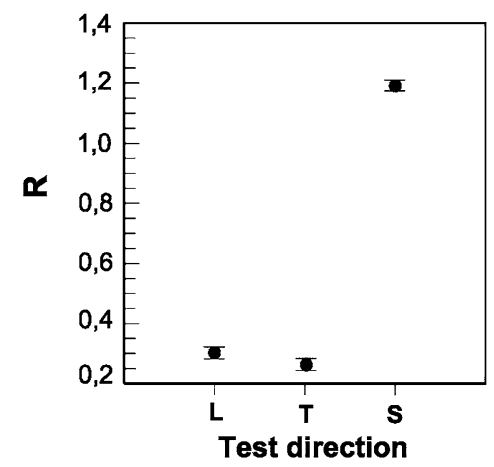

(a)

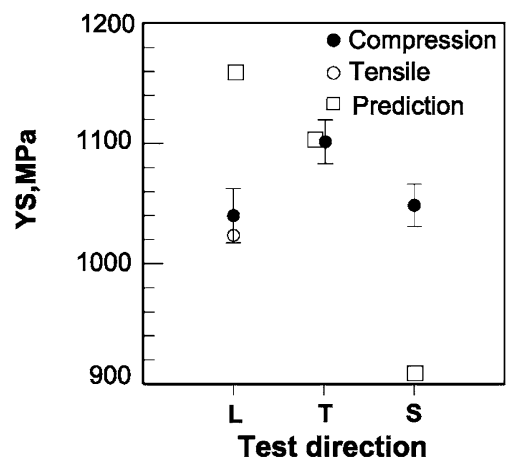

(b)

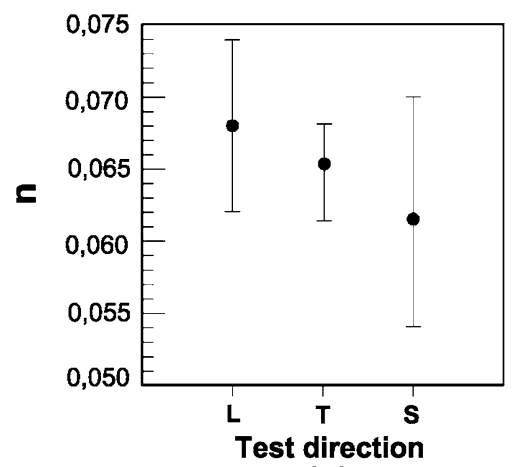

(c)

Fig. 6-Variation of compression properties with loading orientation: $(a)$ transverse plastic strain ratio, $(b)$ yield strength, $(c)$ strain hardening.

The great discrepancy between Hill's theory and the current results could be attributed to various causes. First, the Hill's theory ensures compatibility between grains by assuming homogeneous straining; this causes discontinuity of stress at grain boundaries which is not consistent with requirement for equilibrium. Second, the Hill's model is rigid plastic, and then the elastic properties of the crystallites are neglected. The elastic anisotropy could also play a significant role in the early stages of plasticity, because grains oriented with a stiff direction parallel to the tensile axis will bear a greater proportion of the applied load. Therefore, the Hill's theory does not incorporate the full effect of texture on the yield strength. Moreover, previous experimental results have also shown that the Hill's theory often 
overestimates the effect of $R$ value on YS. ${ }^{[17]}$ On the other hand, a considerable amount of experimental work has demonstrated that neither the grain morphology nor the inclusions morphology significantly influences on the YS but fracture toughness and ductility. ${ }^{[18-}$ ${ }^{23]}$ It is worth mentioning the strong similarity between the present results on the variation of YS with test direction, Figure 6(b), and those previously reported for a normalized hot-rolled steel. ${ }^{[20]}$

The variation of strain hardening exponent, $n$, with the orientation of the compression axis is shown in Figure 6(c). The variation of $\mathrm{n}$ values with compression direction is small. Moreover, the differences cannot be considered statistically significant due to the large scatter of $n$ values that exist in each orientation.

\section{B. Hardness Tests}

Figure 7(a) shows the effect of the indentation plane on the Vickers hardness. It is observed that the hardness is slightly lower on the T-L plane than those on the T-S and L-S planes in which almost identical values were obtained. These differences in hardness are consistent with the small variations of YS with test direction. Effectively, assuming that $\mathrm{Hv}$ and YS are approximately related by a factor of $3(\mathrm{Hv} \approx 3 \mathrm{YS}),{ }^{[24]}$ the values of YS obtained from hardness values of T-S, L-S and T-L planes in Figure 7(a) are 1166, 1150, and $1117 \mathrm{MPa}$, respectively. These values follow the same trend as those predicted according to the Hill's model; however, its

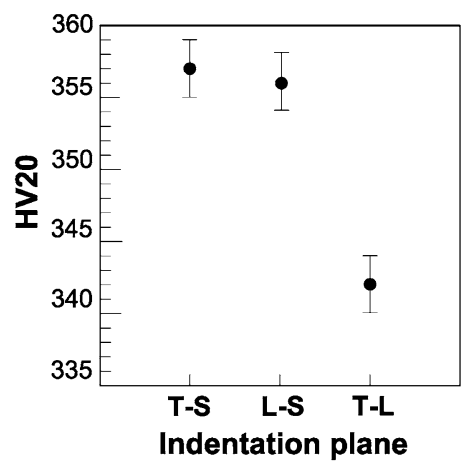

(a)

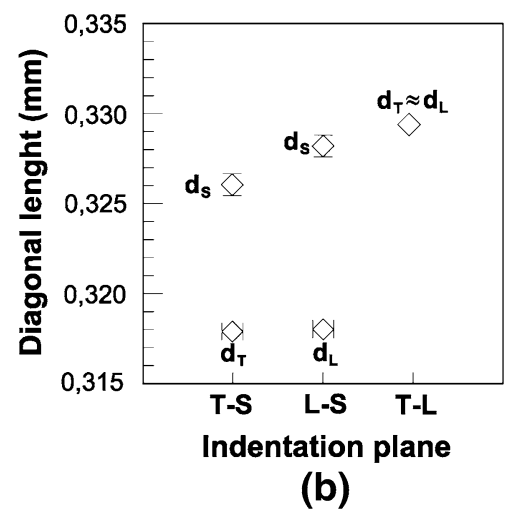

Fig. 7-Effect of the indentation plane on: (a) HV20 hardness number, (b) diagonal length of HV20 impressions; $d_{\mathrm{L}}, d_{\mathrm{T}}$, and $d_{\mathrm{S}}$ are the diagonal length in $\mathrm{L}, \mathrm{T}$, and $\mathrm{S}$ directions, respectively. magnitudes are different, particularly, that for $\mathrm{S}$ test direction. On the other hand, the experimental results of YS of compression tests are also different from those deduced from hardness tests, particularly, that for L test direction.

It was also noted (Figure 7(b)) that the diagonals of the indentation on T-S and L-S planes are different systematically. The diagonals in $\mathrm{S}$ direction are always higher than those in $\mathrm{T}$ and $\mathrm{L}$ directions for T-S and L-S indentation planes, respectively. For indentations on T-L plane, no systematic difference in the diagonals was observed. These differences in the indentation diagonals are consistent with the above described measurements of transverse plastic strain ratios in compression tests in spite of the complex stress state beneath the indentation.

\section{Wedge-Splitting Tests}

Table II resumes the results of WST for the six notch orientations. In the second column of the table, the average and standard deviation values of the failure splitting load of four tests are given. All specimens fractured before the general yield load, $P_{\mathrm{GY}}=5612 \mathrm{kN}$, which has been previously obtained from the finite element analysis as the load at which the full ligament begins to plastically deform. Two failure modes are reported in the last column: one in which fracture propagates along the notch plane, as is the case for LT, TL, ST, and SL notch orientations and that another, for LS and TS orientations, in which fracture propagates along two branches normal to the notch plane, i.e., parallel to the L-T plane. Moreover, the macroscopic aspect of the fracture of TL, SL, and LS specimens present similar features to those of LT, ST, and TS specimens, respectively.

Figure 8 shows the fractographic details of the fracture surface of LT specimen. Figure 8(a) reveals the presence of two groups of delaminations or secondary fractures, that one of large delaminations regularly spaced through the specimen thickness and that one of small delaminations heterogeneously distributed between the large delaminations. The delaminations are parallel to L-T plane. Figures 8(a) and (b) show that the fracture between delaminations, i.e., the main fracture, has occurred by a ductile mechanism, whereas Figures $8(\mathrm{~b})$ and (c) reveal that the delaminations have occurred by a brittle mechanism. Electron backscattering diffraction (EBSD) grain orientation image in Figure $8(\mathrm{~d})$ reveals that the delamination follows a mainly intergranular path.

Figure 9 shows the fractographic details of the fracture surface of ST and TS specimen. The fracture of ST specimen, occurring along the notch plane (Figures 9(a) and (b)), presents an identical aspect, Figure 9(c), to that showed at the surface of delamination, Figure 8(c), for LT specimen. The fracture of TS specimen (Figures 9(d) and (e)) initiates at one point or at two points, one on each side of the symmetry axis of the notch, and then propagates catastrophically along one or two branches orthogonal to the notch plane, i.e., parallel to L-T plane. The fractographic features of the fracture surface of TS specimen (Figure 9(f)) are similar 
Table II. Experimental Results and Finite Element Analysis Results of Wedge-Splitting Tests

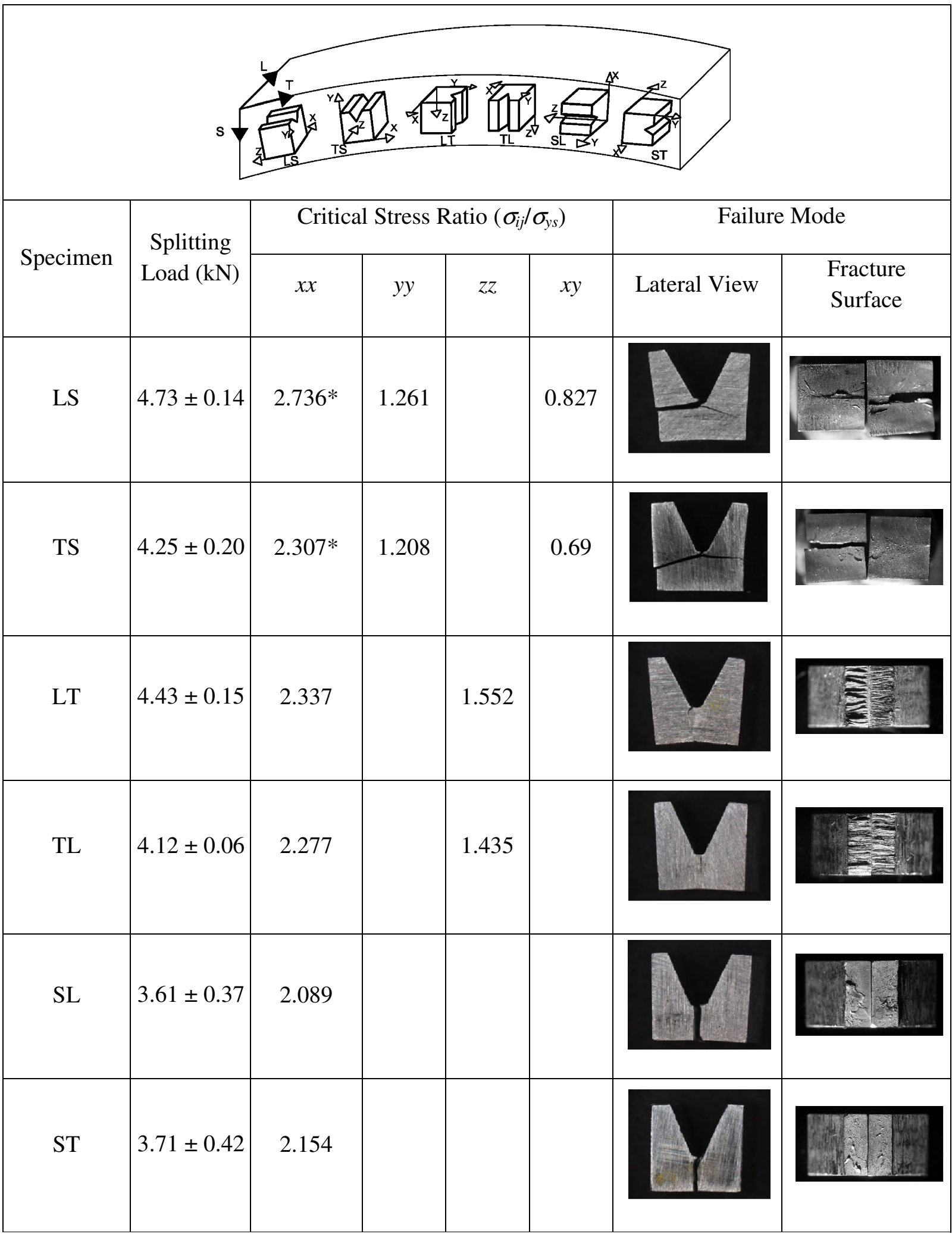

*The critical value of this stress component for crack propagation at S direction should be higher than that in which crack branching actually occurred. 

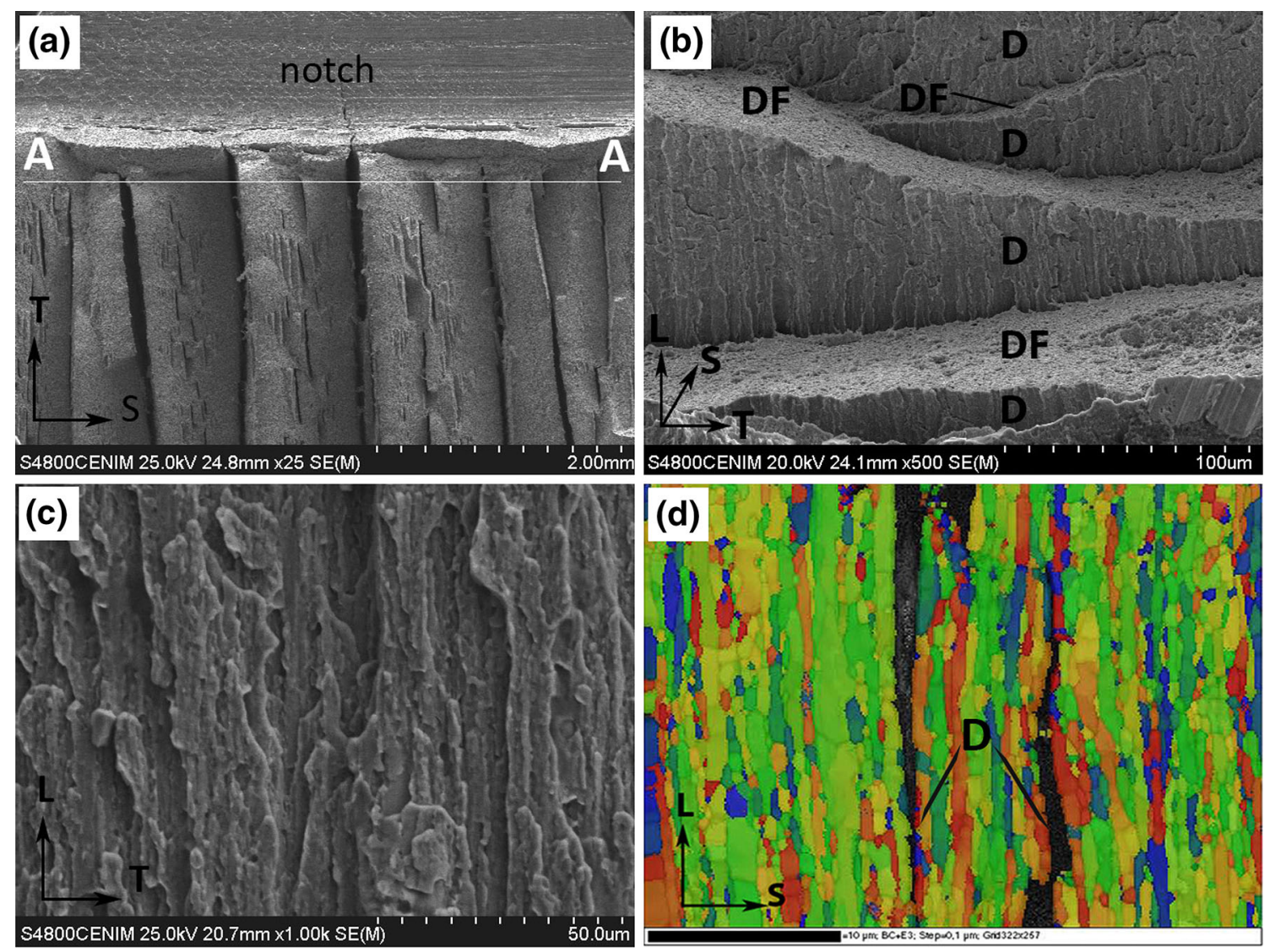

Fig. 8-Fractographic details of fracture surface of LT specimen: (a) SEM image showing the general aspect of delaminations. (b) SEM image showing the delaminations (D) and the ductile character of the main fracture (DF). (c) SEM image at higher magnifications of the delamination surface. $(d)$ EBSD grain orientation image of A-A section of (a) showing the preferably intergranular path of the delaminations.

to those of the delaminations of LT specimen in Figure $8(\mathrm{c})$ and of the fracture surface of ST specimen in Figure 9(c). From this fractographic analysis, it is evident that the planes parallel to L-T plane are planes of weakness.

It is well known that there are two factors enhancing the formation of delaminations in steels: the preferred orientation of the grains and their morphology and arrangement in the mesoscopic scale. ${ }^{[21,25-27]}$ However, it has been shown that the morphology and arrangement of grains rather than texture are the more important factor controlling the delamination formation. ${ }^{[21]}$ Both factors are considered below to explain the cause of the delaminations and crack branching in PM2000 alloy.

The above transverse plastic strain ratio measurements in compression tests have shown that when a sample is plastically deformed in $\mathrm{L}$ or $\mathrm{T}$ direction $(\langle 110\rangle$ crystallographic direction), the cross section of the samples presents a strong tendency to deform in plane strain conditions in the L-S or T-S planes, respectively, rather than axially symmetric flow. Previous Bishop-Hill type crystallographic analysis has demonstrated that for [110] fiber-textured BCC materials, the necessary stress to produce axially symmetric flow is $3 / 2$ of that required for plane strain flow. ${ }^{[28]}$ Consequently, the material presents a strong tendency to deform by plane-strain flow. Moreover, using the same analysis type, it was also demonstrated that intergranular transverse tensile stres- ses act perpendicular to the $\{001\}$ planes parallel to the applied stress. ${ }^{[29]}$ Diffraction studies have corroborated that the transverse stresses acting on longitudinally aligned planes are tensile on (100) planes and compressive on (110) planes, being their absolute magnitude of the order of $1 / 5$ and $1 / 3$ of the material flow stress. ${ }^{[30,31]}$ Having into account that the L-T plane is a (100) plane and that the $\langle 110\rangle$ crystallographic direction is the main direction in $\mathrm{L}$ and $\mathrm{T}$ directions, it could be thus expected that the material texture enhances the propensity to delamination for LT and TL specimens or to branching for LS and TS specimens.

In order to evaluate the last assertion, it is necessary to perform additional experimental work aimed to separate the effect of microstructural morphology from texture.${ }^{[32]}$ Following the reviewer's suggestions, ${ }^{[32]}$ WS specimens were machined with the notch plane parallel to other two (110) planes that are equivalent crystallographically but not morphologically. In accord with the reviewer, this involves two 45 degree rotations prior to machining the notch, Figure 10. It could be anticipated that if the specimen delaminates or fractures along the crystallographically equivalents (001) planes, which is not the L-T plane, the texture would be the main cause of the delamination or branching. If the specimen delaminates along the of L-T plane, the microstructure morphology would be the main cause of the delaminations. WS specimens with three notch positions 

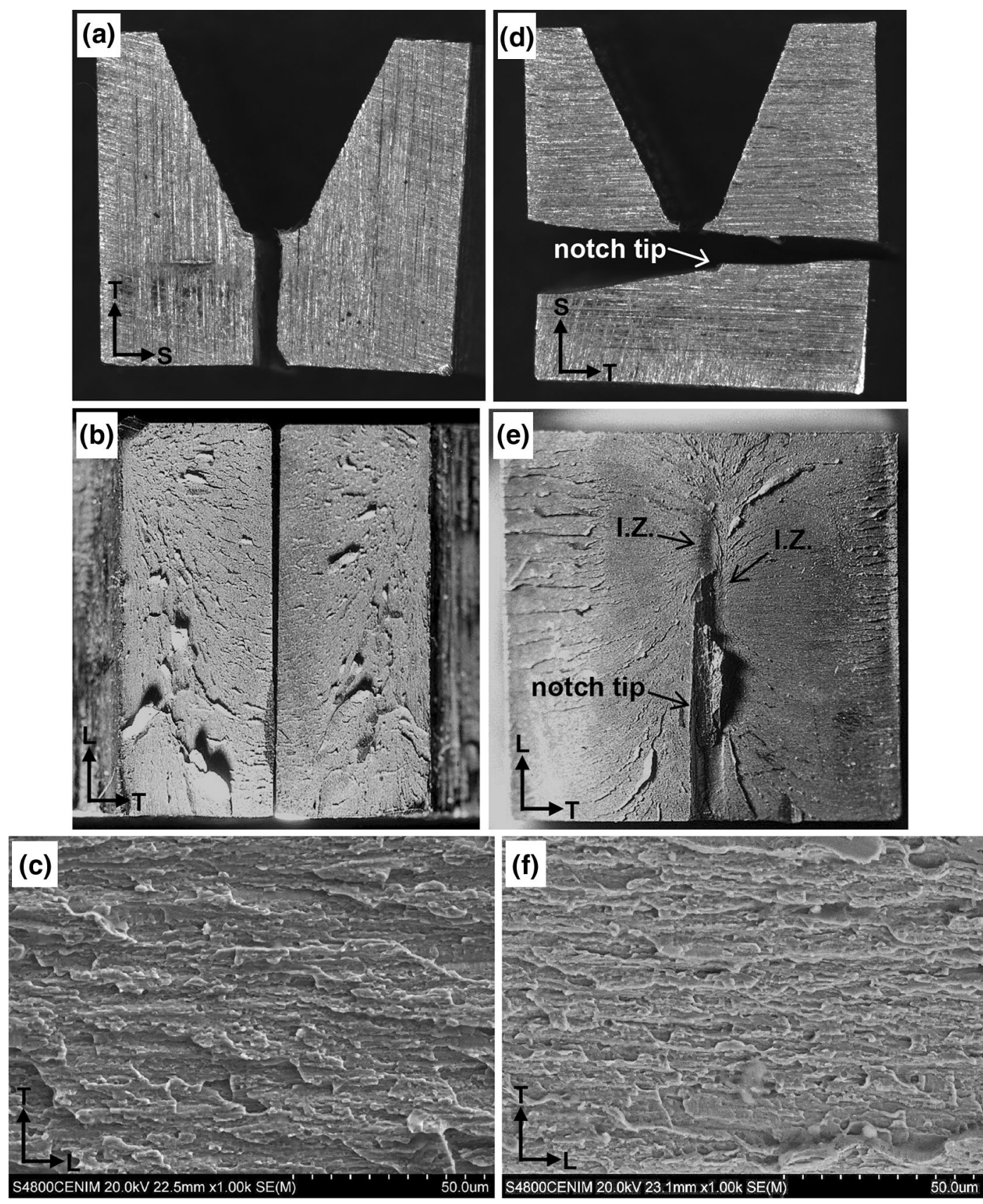

Fig. 9-Fractographic details of fracture surface of ST and TS specimens: (a) Optical macrograph showing the lateral view of fracture of ST specimen. (b) Optical macrograph showing the general appearance of the fracture surface of ST specimen. (c) SEM image at higher magnifications of the fracture surface of ST specimen. $(d)$ Optical macrograph showing the lateral view of fracture of TS specimen. (e) Optical macrograph showing the general appearance and the initiation zones (IZ) of the fracture in the bottom fragment in (d). ( $f$ ) SEM image at higher magnifications of the fracture surface of TS specimen.

designated according to Figure 10 as $\mathrm{XY}, \mathrm{XZ}$, and YX were machined and then tested in the same conditions as the other WS specimens. It is expected that the crystallographic orientations of the notch of XY, XZ, and YX in Figure 10 are equivalent to those of LT, TS, and TL in Figure 3, respectively.

Microtexture analysis was carried out by the EBSD technique in X-Z plane (see Figure 10) in order to be compared with that previously obtained for the L-S plane (see Figure 1). ${ }^{[10]}$ The results were represented by means of an inverse pole figure (IPF) maps which give the orientation of a macroscopic direction with respect to a specific crystal direction. Figures 11(a) and (b) illustrate the IPF maps for L-S and X-Z planes, indicating the $\langle u v w\rangle$ directions parallel to the $\mathrm{L}, \mathrm{T}$, and $\mathrm{S}$ and $\mathrm{X}, \mathrm{Y}$, and $\mathrm{Z}$ directions, respectively. Figure 11(a) reveals that more than 80 pct of the indexed grains presents the $\langle 110\rangle$ parallel to L direction; 
however, in $\mathrm{T}$ direction the crystalline direction of one half of indexed grain is parallel to $\langle 110\rangle$ direction whereas that of the other one half is oriented parallel to $\langle 111\rangle$ direction. In $\mathrm{S}$ direction about $70 \mathrm{pct}$ of the indexed grains, the crystalline direction is parallel to $\langle 100\rangle$ direction and that of the remainder grains is parallel to $\langle 111\rangle$ direction. Figure 11(b) reveals the presence of the same orientations than those in Figure 11(a) but results much less intense. Comparing Figures 11(a) and (b) results, it is evident that the morphology of the grains in the L-S plane is more elongated that in the $\mathrm{X}-\mathrm{Z}$ plane.

Figure 12 shows the fractographic details of XY specimen. Fracture initiates in various points of the notch tip and then propagates along a plane tilted $\approx 30$ deg regarding to the notch plane, Figure 12(a). Figure 12(b) shows that the longitudinal axis of the fracture facets is inclined $\approx 45 \mathrm{deg}$ to the macroscopic direction of the fracture propagation. The microscopic features of the fracture surface in Figure 12(b) are

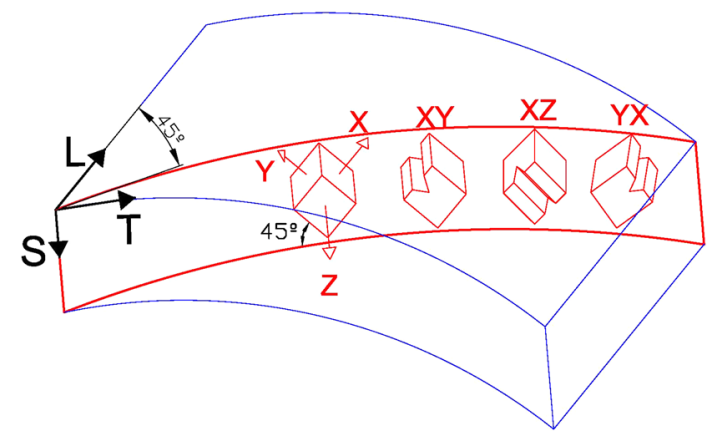

Fig. 10-Drawing showing the orientation and designation of wedge splitting specimens with notch orientation modified. Note that the crystallographic orientations of the notch of XY, XZ, and YX specimens are equivalent to those in Fig. 3 of LT, TS, and TL specimens, respectively. similar to those showed in Figures 8(c) and 9(f) for the surfaces of delamination and crack branching of LT and TS specimens. The material microstructure below the fracture profiles along $\mathrm{AA}$ and $\mathrm{BB}$ sections (see Figure 12(a)) presents an elongated morphology, Figures 12(c) and (d). These results suggest that the fracture has occurred along the L-T plane.

Figure 13 shows the fractographic details of $\mathrm{XZ}$ specimen. The fracture initiation point is located at the notch tip, and then the fracture propagates following a stepped path through the specimen ligament, Figure 13(a). The stepped path consists in brittle cracks separated by ductile walls, Figures 13(b) and (c). The longitudinal axis of the facets of brittle cracks is inclined $\approx 45 \mathrm{deg}$ regarding to the macroscopic propagation direction of the main fracture. Moreover, the fractographic features of the surface of brittle cracks, Figure 13(b), are similar to those shown in Figures 8(c) and 9(f). The fracture profile parallel to the notch basis (AA section in Figure 13(a)) reveals that the brittle cracks are tilted $\approx 30$ deg regarding to the notch plane whereas the ductile walls are inclined $\approx 90$ deg, Figure 13(c). Furthermore, the brittle cracks have attempted to progress into the material in spite of the presence of ductile tears, Figure 13(c). In higher magnification, it is observed in Figure 13(d) that fracture in brittle cracks run parallel to the longitudinal axis of the grains following an intergranular path, inset of Figure 13(d). The fracture profile along the specimen ligament (BB section in Figure 13(a)) is more smooth than the profile along the AA section. Moreover, the grains below the fracture profile present an equiaxial morphology, Figure 13(e). These results also suggest that the fracture has occurred along the L-T plane.

The above results confirm that L-T plane is a microstructurally weak plane; however, such results do not allow an assessment of the effects of microstructure morphology either texture or of the internal
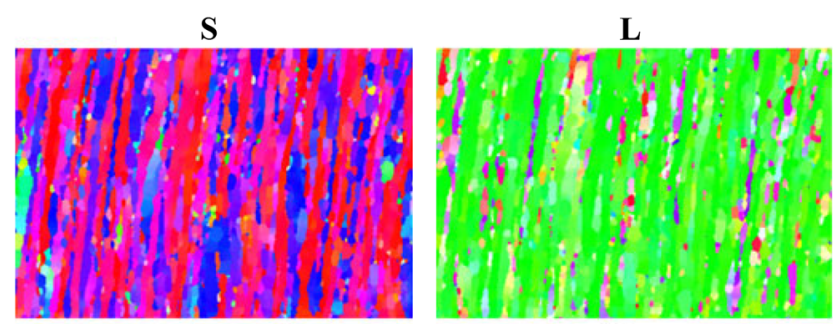

(a)
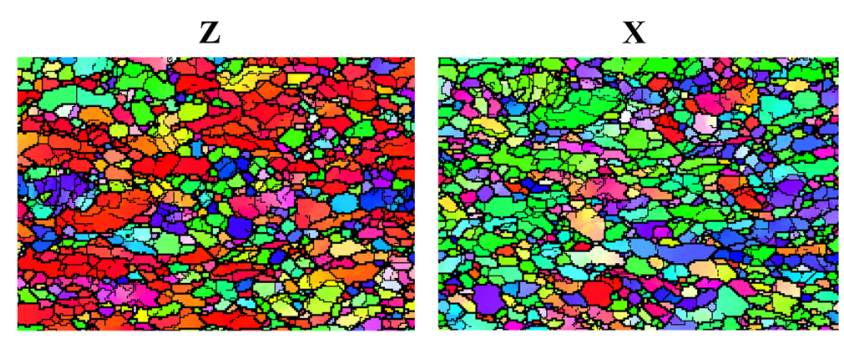

(b)
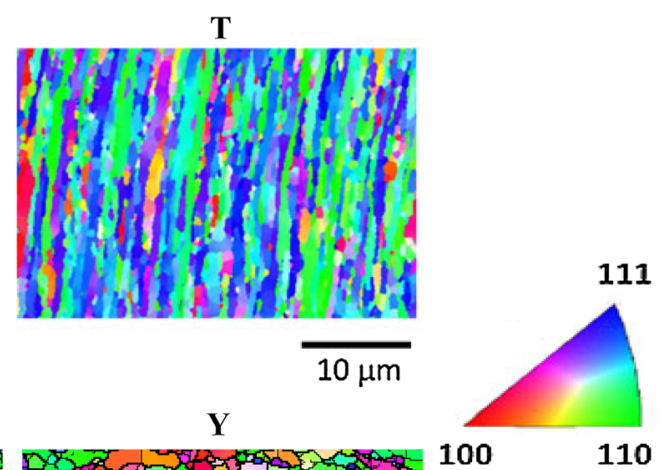

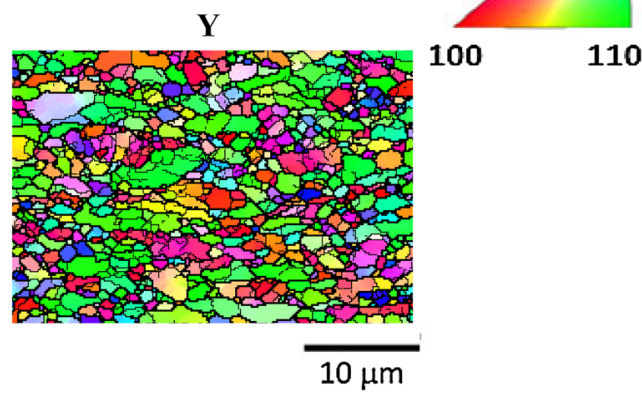

Fig. 11-Inverse pole figure (IPF) maps in: (a) L-S plane (see Fig. 1), (b) X-Z plane (see Fig. 10). 


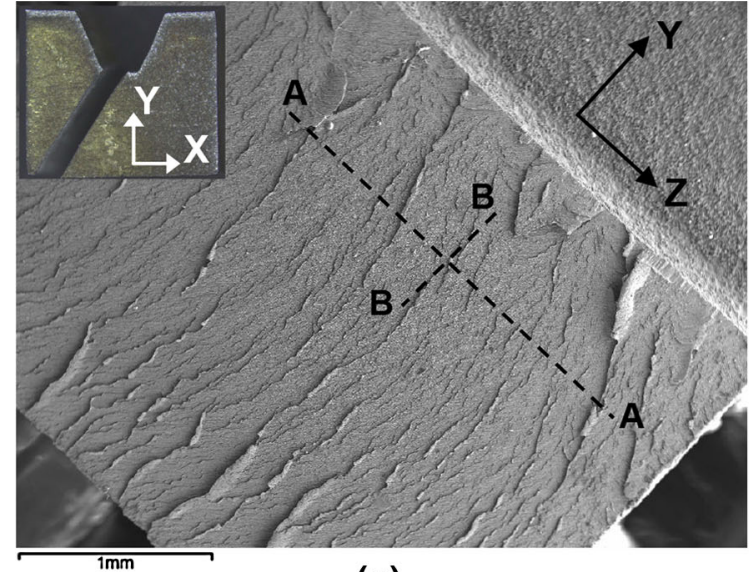

(a)

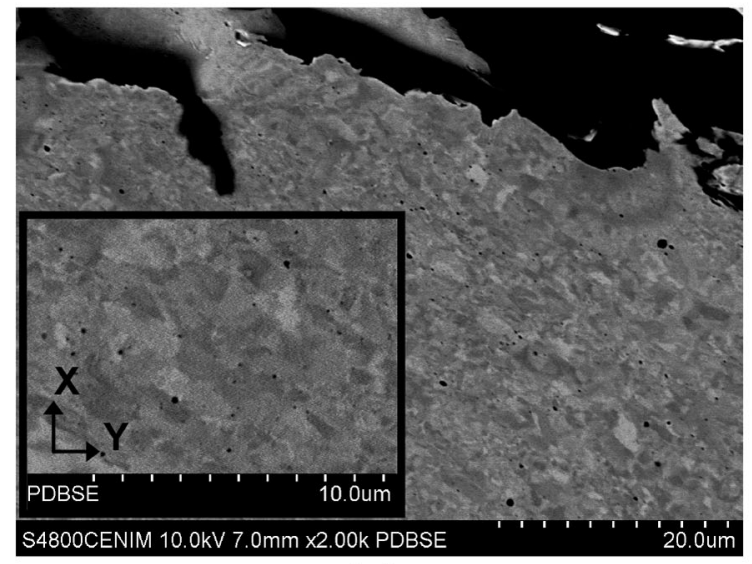

(c)

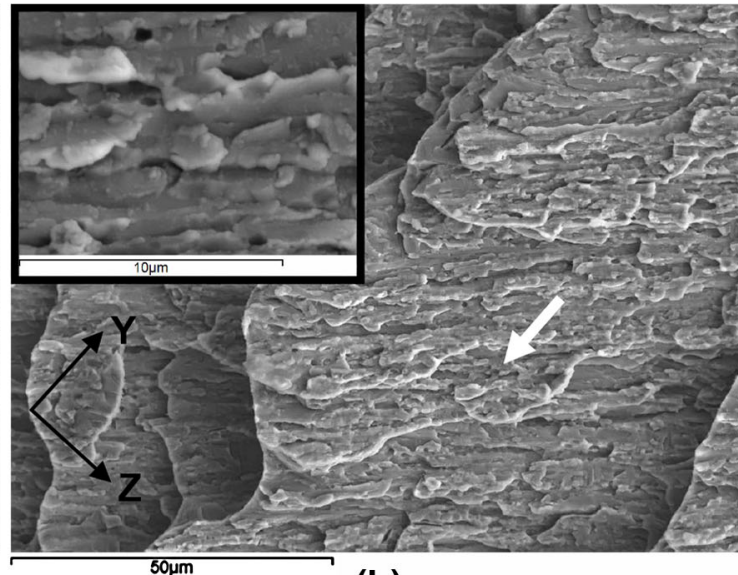

(b)

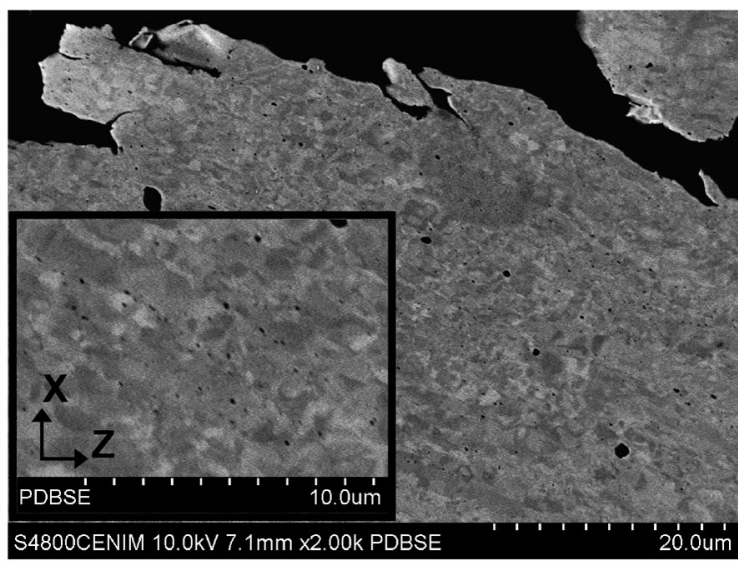

(d)

Fig. 12-Fractographic details of the fracture of XY specimen (see Fig. 10). (a) SEM image showing the macroscopic aspect of the fracture surface. The optical macrograph in the inset shows the fracture profile. (b) SEM image showing the microscopic features of the fracture surface. The white arrow indicates the fracture propagation direction. Further details of the fracture surface in higher magnifications are shown in the inset. (c) SEM image of the fracture profile of BB cross section indicated in (a). Further details of the fracture surface in higher magnifications are shown in the inset. (d) SEM image of the fracture profile of AA cross section indicated in (a). Further details of the fracture surface in higher magnifications are shown in the inset.

texture-induced stresses on the delaminations or crack branching. Firstly, because of the microstructural morphology is distinctively different. In L-S plane, it is markedly elongated, Figure 11(a), whereas in the X-Z plane, it is nearly equiaxial, Figure 11(b). On the other hand, the texture in L-S plane is also significantly different from that of X-Z plane, since the texture intensity in the latter plane is much less than that of the former.

Subsequently, we consider what stress state can enhance the delamination or the branching of the material. Figure 14 shows typical contours around the notch tip of $\sigma_{x x}, \sigma_{y y}, \sigma_{z z}$, and $\sigma_{x y}$ stress components. The stress distributions along $\mathrm{X}$ direction for LT specimens and along $\mathrm{Y}$ direction for TS specimens are shown in Figures 15(a) and (b), respectively. In this regard, and as outlined above, the finite element model is always the same, regardless of the notch position because of the isotropy assumption. The reason to differentiate between LT and TS specimens lies in which the macroscopic fracture mechanism is different and then controlled by different stress components. In the third column of Table II, the maximum values of the stress components at the fracture instant relevant to the failure mode are given. In order to explain the fracture propagation along the notch plane for LT, TL, ST, and SL notch orientations, it is considered that the stress distribution of $\sigma_{\mathrm{xx}}$ stress component (Figures 14(a) and 15(a)) would be the most appropriate component to explain the obtained results.

The fracture propagation along two branches normal to the notch plane for LS and TS notch orientations could be explained by the distribution of $\sigma_{y y}$ stress component ahead of the notch tip, Figures 14(a) and 15(a) but could also be justified by the combination of both the $\sigma_{x y}$ stress and $\sigma_{y y}$ stress components to both sides from the notch tip Figures 14(b) and 15(b). In this regard, it must be noted that the $\sigma_{x y}$ stress component is maximum on both sides of the notch tip and with equal magnitude than $\sigma_{y y}$ stress component, Figure 14(b). This is consistent with the presence (Figure 9(e)) of two fracture initiation points, one on each side of the notch tip, in TS specimens.

Cook and Gordon analyzed theoretically the problem of the crack branching in a hypothetic material with a 


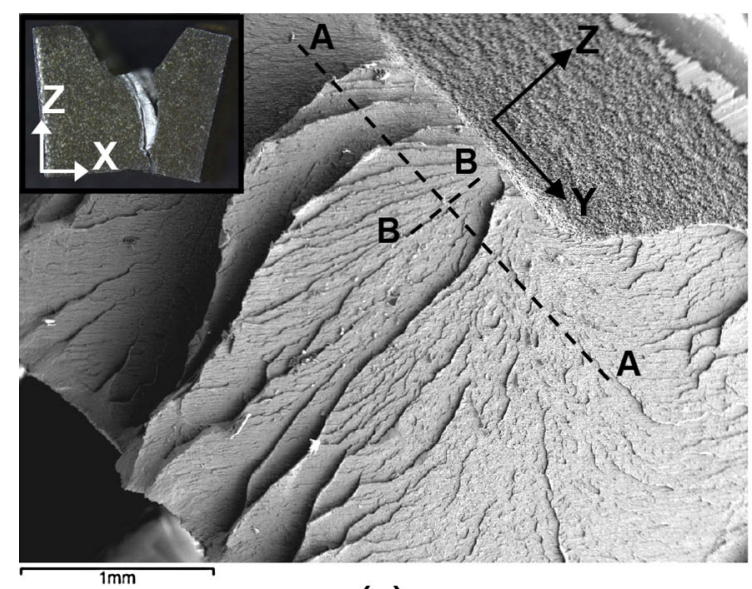

(a)

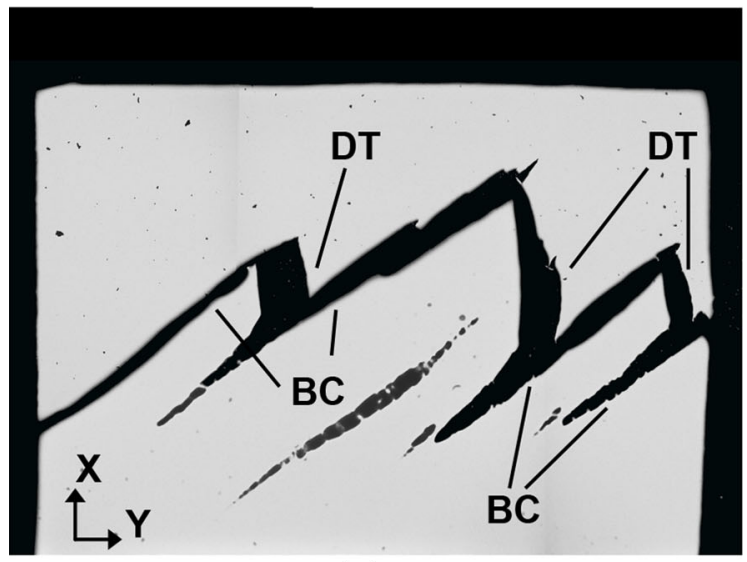

(c)

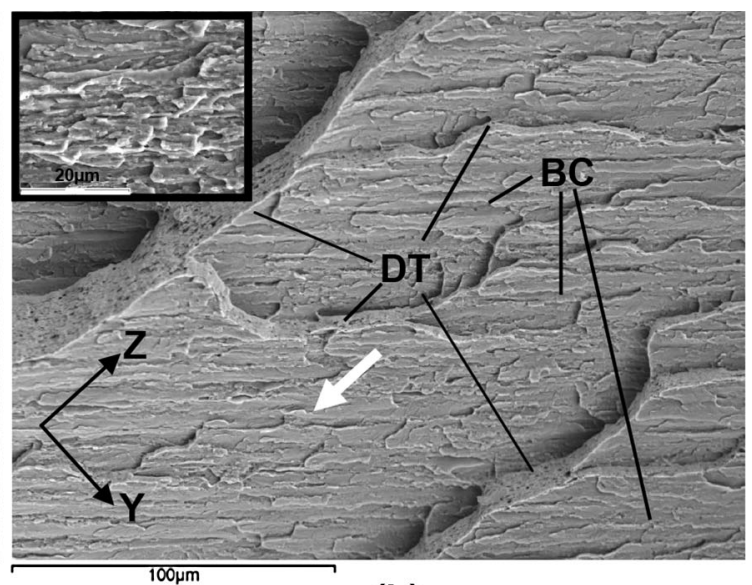

(b)

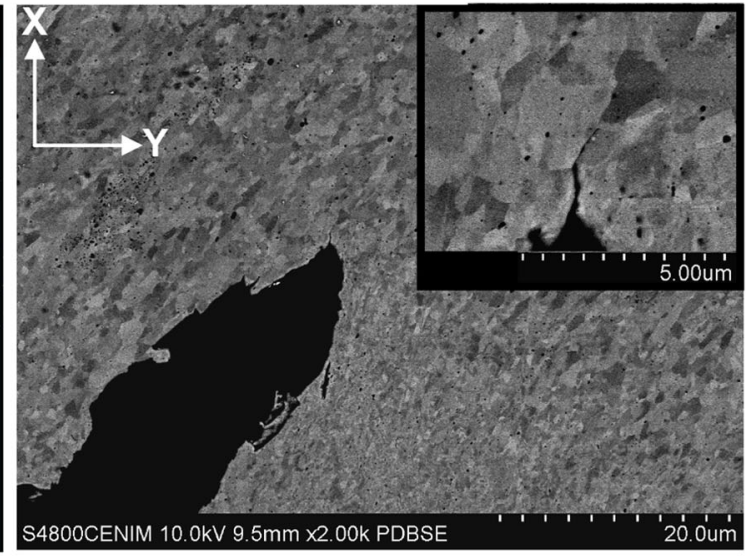

(d)

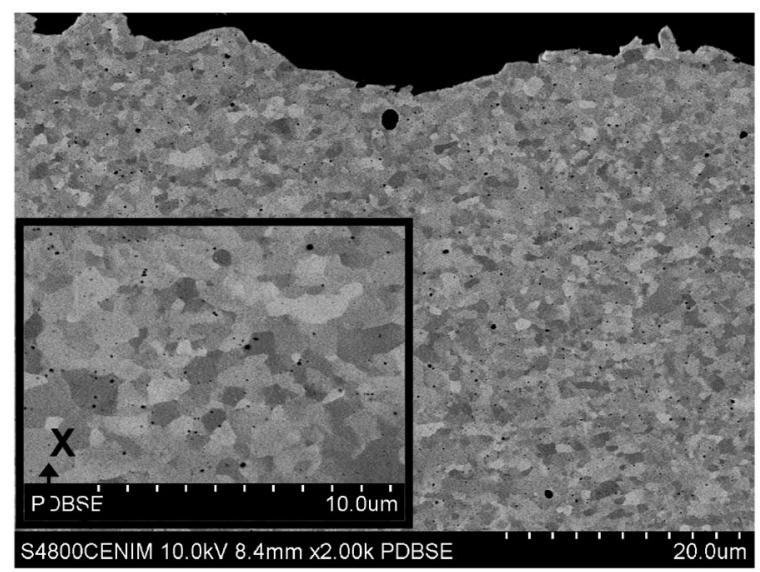

(e)

Fig. 13 - Fractographic details of the fracture of XZ specimen (see Fig. 10). (a) SEM image showing the macroscopic aspect of the fracture surface. The optical macrograph in the inset shows the fracture profile. (b) SEM image showing the microscopic details of the fracture surface with further details of a brittle crack at higher magnifications into the inset. The white arrow indicates the fracture propagation direction. $\mathrm{BC}$, brittle crack. DT, ductile tear (c) Optical image of AA cross section indicated in (a), showing the details of the fracture profile along the Y direction. (d) SEM image showing the details of one of various crack tips at (c) and further details at the inset revealing the intergranular character of the fracture profile. (e) SEM image showing the details of the fracture profile at the BB cross section indicated in (a).

bond plane normal to the crack in which the adhesion was not perfect. ${ }^{[29]}$ They consider three possibilities:

1. Very weak bond plane. The fracture begins ahead of the notch tip at the intersection of the bond plane with the notch plane where the $\sigma_{y y}$ stress component is a maximum (Figures 9(a) and 10(a)). Subsequently, and in agreement with Cook and Gordon, the branch propagates, until the value of the stress intensity factor is lower than the critical value for crack propagation. Finally, the material 

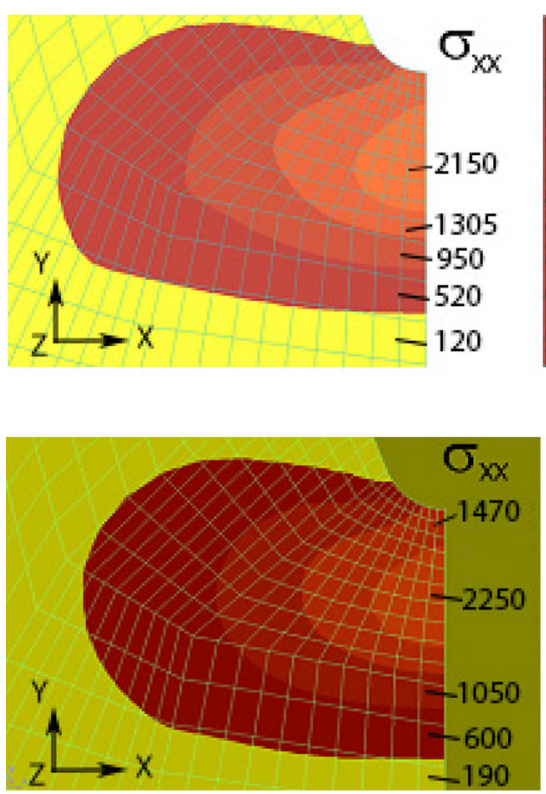
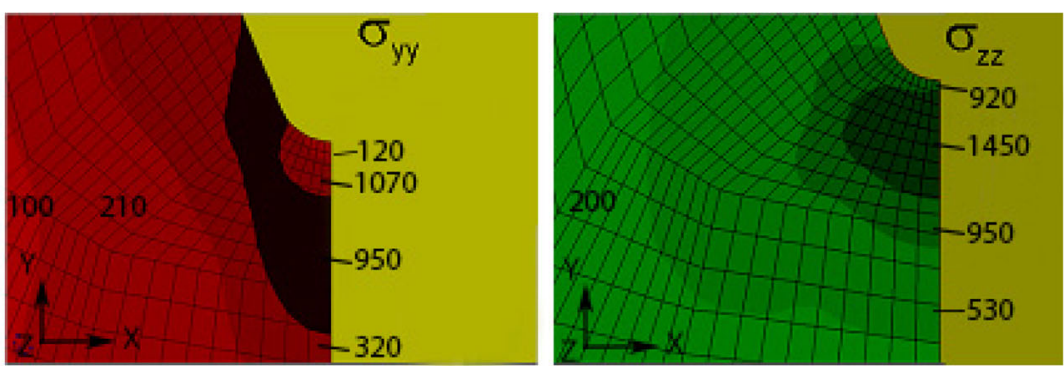

(a)
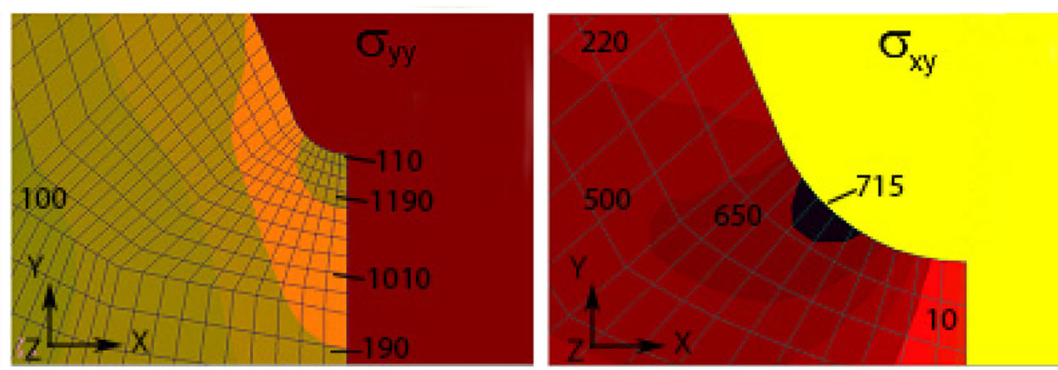

(b)

Fig. 14 Contours of the stress components: $(a)$ TL specimen $\left(P_{\mathrm{sp}}=4.12 \mathrm{kN}\right),(b)$ TS specimen $\left(P_{\mathrm{sp}}=4.25 \mathrm{kN}\right)$. The numbers on the plots indicate the stress level.

will deform, but without the notch effect, until the fracture reinitiates again.

2. Mid-strong bond plane. If the bond plane has survived the maximum value of the $\sigma_{y y}$ stress component ahead of the notch tip, the fracture could be controlled by the $\sigma_{x y}$ stress component. The maximum values of $\sigma_{x y}$ stress component are symmetrically located off the notch axis on the notch surface and are numerically similar to that of $\sigma_{y y}$ stress component at the same location, Figures 9(b) and 10(b). Cook and Gordon considered that this possibility rather improbable and only plausible in case the fracture is propagation controlled. However, and as it is the case for LS and TS notch orientations, the fracture can be initiation-controlled at the notch tip, in which case the event is probable to occur. Therefore, for LS and TS notch orientations, the fracture can be determined by $\sigma_{y y}$ and $\sigma_{x y}$ stress components. In this case, the fracture initiates and catastrophically propagates at one half or both halves of the specimen beside the notch tip, Figure 11.

3. Strong bond plane. If the bond plane does not fail, then the main crack will cross it, and the fracture would extend as in a homogeneous medium.

It is noteworthy that using the first two methods a notable improvement of the fracture toughness (upper shelf) can be obtained. ${ }^{[10,33-35]}$

On the other hand, the $\sigma_{z z}$-stress component induced by the constraint at the crack tip (Figures 14(a) and 15(a)) has been considered as the driving stress for delamination. ${ }^{[20,21,25-27,36-39]}$ Apparently, the results at the last four rows of Table II do not support this explanation, because the $\sigma_{z z} / \sigma_{y s}$ values at fracture of LT and TL specimens, 1.552 and 1.435 , respectively, are considerably lower than the $\sigma_{x x} / \sigma_{y s}$ values of SL and ST specimens, 2.08 and 2.154, respectively. However, it must be taken into account that the texture-induced stress intensification for LT and TL specimens has been neglected in the finite element analysis. It is also possible, like in the case of the crack branching that the delamination initiates when a critical shear stress is reached and then extends by the action of $\sigma_{z z}$-stress component. Therefore, it can be concluded that delamination could effectively be a $\sigma_{z z}$-controlled event, although a contribution from the shear stress to the fracture initiation can still not be discarded.

Previous work of the authors has shown that delamination of an extruded bar of PM2000 alloy without texture was a strain rate-controlled process and that the cause of delamination could be attributed to the hydrogen stored in the material during its particular processing. ${ }^{[40]}$ Moreover, the fracture morphology of the delaminations was very similar to that observed (Figure $8(\mathrm{c})$ ), for the material used in the present study. In order to verify this possibility, additional WST with LT and SL notch orientations and tensile tests of longitudinal specimens were performed at $5 \times 10^{-5}$ and $5 \times 10^{-2} \mathrm{~s}^{-1}$ strain rates. The results indicated that delamination and ductility loss are not a strain ratecontrolled process. These results are consistent with the lower level of hydrogen content of $1.7 \mathrm{ppm}$ of the material used in the present study in comparison with that of $11 \mathrm{ppm}$ of previous work. ${ }^{[40]}$

Taking into account the reported causes for delamination $^{[20,21,25-27,36-39,41]}$ and the present results, it is proposed that the microstructural causes of the delaminations and crack branching for PM2000 alloy are the alignment in the mesoscopic scale of the ultrafine grain structure which is enhanced by both the texture-induced internal stresses and the presence in the grain boundaries 


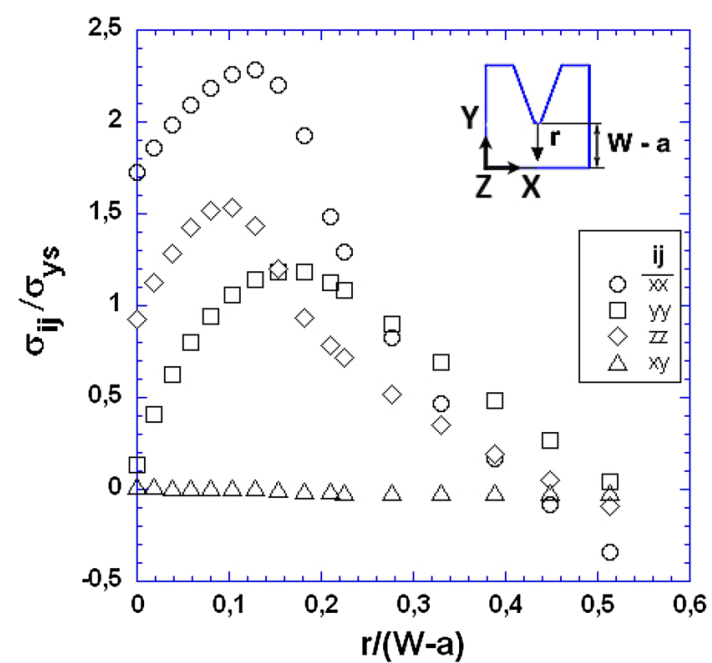

(a)

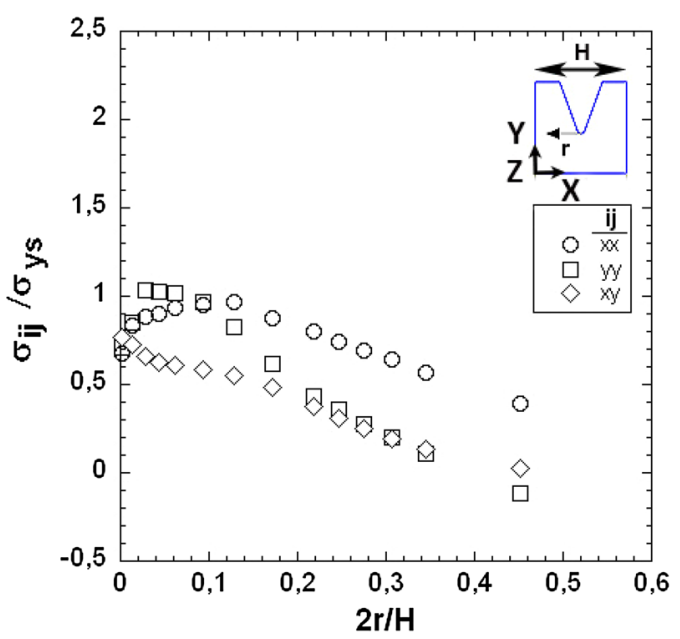

(b)

Fig. 15-Stress distribution below the notch tip along: (a) Y direction for TL specimen $\left(P_{\mathrm{sp}}=4.12 \mathrm{kN}\right),(b) \mathrm{X}$ direction for TS specimen $\left(P_{\mathrm{sp}}=4.25 \mathrm{kN}\right)$.

of yttria dispersoids and impurity contamination. On the other hand, although the driving stress for the delamination and crack branching is the normal stress to the delaminations and branches, respectively, the effect of the shear stress cannot still discarded.

For the evaluation of the anisotropy of the material toughness, the splitting loads in Table II were ranked in descending order according to both the failure mode and the fracture micromechanism, as follows:

- Crack propagation along the notch plane-ductile fracture with delaminations: $P_{\mathrm{sp}}(\mathrm{LT})>P_{\mathrm{sp}}(\mathrm{TL})$.

- Crack propagation along the notch plane-intergranular brittle fracture: $P_{\mathrm{sp}}(\mathrm{ST})>P_{\mathrm{sp}}(\mathrm{SL})$.

- Crack propagation normal to the notch plane - intergranular brittle fracture: $P_{\mathrm{sp}}(\mathrm{LS})>P_{\mathrm{sp}}(\mathrm{TS})$.

The higher splitting load for LT (ST) notch orientation in comparison with TL (SL) notch orientation could be explained by the combination of two effects, the lower effective grain projected length and the slight lower yield strength. The significant difference in splitting load between LT(TL)- and ST(SL)-notched specimens is due to the differences in the fracture mechanism. From the results of splitting load and failure mode of LS- and TSnotched specimens, it is also clear that the splitting load for fracture propagation along the notch should be higher than that for actual crack branching of 4.73 and $4.25 \mathrm{kN}$, respectively. Therefore, in case the fracture occurred along the notch plane and not via branching as actually occurred, the fracture toughness would be higher for LS- and TS-notched specimens.

\section{CONCLUSIONS}

The anisotropy in the mechanical behavior of a FeCrAl ODS ferritic alloy supplied as a tube of $100 \mathrm{~mm}$ in diameter and $7 \mathrm{~mm}$ in thickness was investigated using cubic and wedge splitting specimens. The following results were obtained:

1. The YS values obtained from compression specimens taken in longitudinal and short directions are very similar from each other and on average $\sim 80 \mathrm{MPa}$ lower than the specimen taken in tangential direction.

2. The values of transverse strain ratio obtained from compression specimens taken in tangential and longitudinal directions indicated a strong tendency of the material to deform in plane strain conditions on T-S and L-S, respectively, while that of compression specimen in short direction presented a nearly isotropic behavior.

3. The microstructural causes of the delaminations and crack branching are the alignment in the mesoscopic scale of the ultrafine grain structure which is enhanced by both the texture-induced internal stresses and the presence in the grain boundaries of yttria dispersoids and impurity contamination.

4. The driving stress for the delamination and crack branching is the normal stress to the delaminations and branches, respectively; however, the effect of the shear stress component cannot still discarded.

5. In the case that the fracture occurred along the notch plane, the fracture toughness would be higher for LS- and TS-notched specimens.

\section{ACKNOWLEDGMENTS}

Financial support of the Spanish Ministerio de Educación y Ciencia through a Coordinated Project in the Energy Area of Plan Nacional 2006 (ENE2006-15170C02) is gratefully acknowledged. The authors are grateful to the Editor, Key-Reader and Reviewers efforts and constructive comments that have significantly improved the original manuscript.

\section{REFERENCES}

1. A. Kimura, R. Kasada, N. Iwata, H. Kishimoto, J. Isselin, C.H. Zhang, P. Dou, and J.H. Lee: Proc. of the 2009 International 
Congress Advances in Nuclear Power Plants, Tokyo, Japan, 2009, pp. $9220-25$.

2. G.H. Gessinger and O. Mercier: Powder Metall. Int., 1978, vol. 10, p. 203.

3. S. Ukai, M. Harada, H. Okada, M. Inoue, S. Nomura, S. Shikakura, T. Nishida, M. Fujiwara, and K. Asabe: J. Nucl. Mater., 1993, vol. 204, pp. 74-80.

4. M.J. Alinger, G.R. Odette, and G.E. Lucas: J. Nucl. Mater., 2002, vols. 307-311, pp. 484-89.

5. R. Kasada, S.G. Lee, J. Isselin, J.H. Lee, T. Omura, A. Kimura, T. Okuda, M. Inoue, S. Ukai, S. Ohnuki, T. Fujisawa, and F. Abe: $J$. Nucl. Mater., 2011, vol. 417, pp. 180-84.

6. M.S. Joo: Ph.D. Thesis, Pohang University of Science and Technology, Korea, 2012, pp. 38-58.

7. P. Cizek and B.P. Wynne: Mater. Sci. Eng. A, 1997, vol. 230, pp. 88-94.

8. D.N. Lee: Scripta Metall. Mater., 1995, vol. 32, pp. 1689-94.

9. C. Capdevila, U. Miller, H. Jelenak, and H. Bhadeshia: Mater. Sci. Eng. A, 2001, vol. 316, pp. 161-65.

10. J. Chao, C. Capdevila, M. Serrano, A. García-Junceda, J.A. Jiménez, G. Pimentel, and E. Urones-Garrote: Metall. Mater. Trans. A, 2013, vol. 44A, pp. 4581-94.

11. E. Brühwiler and F.H. Wittmann: Eng. Fract. Mech., 1990, vol. 35 $(1 / 2 / 3)$, pp. $117-25$.

12. J.F.V. Vincent, G. Jeronimidis, A.A. Kahn, and H. Luyten: $J$. Text. Stud., 1991, vol. 22, pp. 45-57.

13. ASTM-E-399-09: Annual Book of ASTM Standards, vol. 03.01, ASTM International, West Conshohocken, PA, 2011, pp. 502-34.

14. I. Toda-Caraballo, J. Chao, L.E. Lindgren, and C. Capdevila: Script Mater., 2010, vol. 62 (1), pp. 41-44.

15. R. Hill: The Mathematical Theory of Plasticity, Chap 12, Oxford University Press, London, 1950, pp. 317-21.

16. G. Baldi and G. Buzzichelli: Met. Sci., 1978, vol. 12, pp. 459-72.

17. W.F. Hosford: Mechanical Behavior of Materials, Chap 6, Cambridge University Press, New York, 2005, pp. 80-98.

18. I. Kozasu and H. Kubota: Trans. ISIJ, 1971, vol. 11, pp. 321-30.

19. W. Dahl: Steel: A Handbook for Materials Research and Engineering, Fundamentals, Springer Verlag, Berlin, 1972, vol. 1, pp. 247-48.

20. W.B. Morrison: Met. Technol., 1975, vol. 2, pp. 33-41.
21. B. Mintz, W.B. Morrison, P.I. Welch, and G.J. Davies: in Texture of Materials, vol. 2, G. Gottstein, and K. Lücke, ed., Springer Verlag, Berlin, 1978, pp. 465-74.

22. W.A. Spitzig and R.J. Sober: Metall. Trans., 1981, vol. 12A, pp. $281-91$.

23. S.K. Paul and S. Mishra: Met. Mater. Process., 1992, vol. 4 (3), pp. 189-202.

24. W.F. Hosford: Mechanical Behavior of Materials, Chap. 5, Cambridge University Press, New York, 2005, p. 64.

25. W.B. Morrison, B. Mintz, and C. Cochrane: in Preprint of the Paper Presented at the Conf. on "Controlled Processing of HSLA Steels", York University, Paper No. 1, British Steel Corporation, 1976.

26. D.S. Dablowski, P.J. Konkol, and M.F. Baldy: Met. Eng. Quart., 1976, vol. 16, pp. 22-32.

27. B. Mintz: Met. Technol., 1980, vol. 7, pp. 127-29.

28. W.F. Hosford: Trans. TMS AIME, 1960, vol. 230, pp. 12-15.

29. J. Gil-Sevillano: Scripta Metall., 1986, vol. 20, pp. 1111-14.

30. J. Gil-Sevillano, J. Alkorta, D. González, S. Van Petegem, and U. Stuhr: Adv. Eng. Mater., 2008, vol. 10 (10), pp. 951-54.

31. J. Gil-Sevillano, D. González, and J. Martínez-Esnaola: Mater. Sci. Forum, 2007, vol. 550, pp. 75-84.

32. Private communication with referee's comments from Editorial Staff of MMTA (T.M. Pollock, Editor), 2013.

33. A.J. McEvily, Jr and R.H. Bush: Trans. ASM, 1962, vol. 55, pp. 655-66.

34. Y. Kimura, T. Inoue, F. Yin, and K. Tsuzaki: Science, 2008, vol. 320, pp. 1057-60.

35. M. Jafari, Y. Kimura, and K. Tsuzaki: Metall. Mater. Trans. A, 2012, vol. 43A, pp. 2453-65.

36. B.L. Bramfitt and A.R. Marder: in Processing and Properties of Low-carbon Steel, J.M. Gray, ed., Metallurgical Society of AIME, New York, 1972, pp. 191-224.

37. J.D.G. Groom and J.F. Knott: Met. Sci., 1975, vol. 9, pp. 390-400.

38. P. Brozzo and G. Buzzichelli: Scripta Mater., 1976, vol. 10, pp. 235-40.

39. R. Song, D. Ponge, and D. Raabe: Acta Mater., 2005, vol. 53, pp. 4881-92.

40. J. Chao, C. Capdevila-Montes, and J.L. González-Carrasco: Mater. Sci. Eng. A, 2009, vol. 515 (1-2), pp. 190-98.

41. J. Cook and J.E. Gordon: Proc. R. Soc. A, 1964, vol. 282A, pp. $508-20$. 